\title{
Olive semidrying process: oleuropein degradation in relation to sensory bitterness.
}

\author{
Yasin Ozdemir ${ }^{1 *}$, Hakan Yavas², Ugur Ozyurt ${ }^{3}$, Rena I Kosti ${ }^{4}$, Ozge Keskinel ${ }^{5}$ \\ ${ }^{1}$ Department of Food Technology, Ataturk Central Horticultural Research Institute, Turkey \\ ${ }^{2}$ Central Research Institute of Food and Feed Control, Turkey \\ ${ }^{3}$ Department of Food Engineering, Middle East Technical University, Turkey \\ ${ }^{4}$ Laboratory of Hygiene, School of Medicine, Aristotle University of Thessaloniki, Greece \\ ${ }^{5}$ Department of Food Engineering, Ankara University, Turkey
}

\begin{abstract}
Today, treatment with brine or $\mathrm{NaOH}$ is the most common debittering procedures for olive industry. Although these debittering procedures are used widely, they have serious disadvantages such as high salt content of the final product, time consuming process (6-8 months required), degradation of other phenolic compounds, nutrient losses and formation of high amounts of waste water. Semidrying method has been recently introduced as a new debittering method. The aim of the present study was to evaluate the degradation of oleuropein and the sensory bitterness during semidrying of olives in a dryer at $400 \mathrm{C}$ and $600 \mathrm{C}$ with $1.5 \mathrm{~m} / \mathrm{s}$ air flow rate. In this research, oleuropein, hydroxytyrosol and tyrosol content and sensory bitterness of olives have been determined for the first time during semi drying. An acceptable bitterness level and $88.76-91.29 \%$ oleuropein reduction was reached while $31.03-38.24 \%$ weight loss of olive was determined after semi drying process. Debittered olives were obtained with $22.41-28.61 \%$ water content. Results suggest that semi drying with piercing in combination with immersion pre-treatments could be used as an environmentally friendly olive debittering method for the production of higher nutritional value and low or free of salt table olives.
\end{abstract}

Keywords: Oleuropein, Olive bitterness, Hydroxytyrosol, Tyrosol

Accepted on March 26, 2018

\section{Introduction}

Table olive consumption is widespread mainly in the countries of the Mediterranean basin thanks to their favorable organoleptic characteristics [1]. Olives are rich source of phenolic antioxidants [2] including distinctive compounds such as verbascoside, ligstroside, hydroxytyrosol and oleuropein [3,4]. Oleuropein is an intensely bitter glucoside and one of the most important components of olives. However, olives can not be consumed without debittering because of the presence of oleuropein. It is worth mentioning that the content of polyphenols in table olives is highly influenced by the olive variety and the applied debittering process [5].

The fundamental and the most important part of table olive processing is debittering. Olives can be debittered either by the removal of oleuropein in brine or by alkali hydrolysis. Those are the main methods used in the table olive industry. In the first method, oleuropein is removed from olives by keeping olives in brine. In the second method, oleuropein is hydrolyzed to hydroxytyrosol and elenolic acid glycosides by using dilute $\mathrm{NaOH}(0.5$ to $2 \%)$ [4-9]. However, both of the mentioned methods have serious drawbacks. Specifically, the brine debittering process is time consuming (it takes 6-8 months to be completed), and final product has a high salt content (5$7 \%$ ) $[10,11]$. Disadvantages of debittering with $\mathrm{NaOH}$ include the degradation of other phenolic compounds with oleuropein, nutrient losses caused by washing during the removal of excess $\mathrm{NaOH}$ from olives [12,13] and formation of high amounts of waste water $[6,14]$. Thus, there is a need for development of a new shorter debittering process which is environmentally friendly and nutritionaly superior compared to the existing ones.

Despite extensive studies on the optimization of different olive processing techniques, there are only a few studies addressing the production of table olives by drying method. Researchers conclude that the production of table olives by drying could be made only experimentally, although in some Mediterranean countries, villagers produce semidried table olives by using traditional sun drying method for their own consumption [15].

In Italy, black table olives have been produced for many years with a traditional method called "Ferrandina". In this method, over-mature black olives are harvested, immersed in water $\left(90^{\circ} \mathrm{C}\right)$ for 5-10 minutes after being mixed with dry salt for 3 days. Then, olives are dried for about 17 hours in an oven at $50^{\circ} \mathrm{C}[15,16]$. As a result of industrial adaptation studies on Ferrandina method the "Sybaris" method was developed. In Sybaris method, immersion step was replaced with olive cutting in three places and immersion in water for 3-4 weeks. In all of these studies, degradation of oleuropein and its possible fragmentation products such as tyrosol and hydroxytyrosol were not determined either during or after debittering. Thus, the aim of the present study was to determine the change of oleuropein, hydroxytyrosol and tyrosol content and to evaluate sensory bitterness taking into account the reduction of water content in olives during drying.

\section{Materials and Methods}

Gemlik olives, within the orchard of Ataturk Horticultural 
Central Research Institute, were harvested at the 5-6 maturation index (purple color fruit has reached half of the flesh) according to skin and flesh color of olives [17]. Water, oleuropein, hydroxytyrosol and tyrosol content and the evaluated sensory bitterness of raw olives are presented in Table 1.

Before drying, three pre-treatments were applied to olives, while one group was dried without any pretreatment for control $[15,16]$. In Table 2 the application of these pre- treatments before drying process are presented, $2 \mathrm{~kg}$ olive sample was used for control and each pre-treatment. Weight of olive samples were not changed after pretreatments.

Olives were dried until bitterness was reduced to an acceptable level, which was set at 1.5 according to a ten-point sensory scoring scale $[18,19]$. in a dryer at $40^{\circ} \mathrm{C}$ and $60^{\circ} \mathrm{C}$ with $1.5 \mathrm{~m} / \mathrm{s}$ airflow and $16 \%$ relative humidity. The drying rate, oleuropein and its degradation products (hydroxytyrosol and tyrosol) and sensory bitterness were determined by taking samples at 1 hour intervals during drying.

\section{Water content analysis}

Water content of olive samples was determined in a conventional oven at $105 \pm 2^{\circ} \mathrm{C}[20]$.

\section{Oleuropein, hydroxytyrosol and tyrosol analysis}

Oleuropein, hydroxytyrosol and tyrosol content was determined according to the method of Lanza B [21]. $5 \mathrm{~g}$ of olive flesh were homogenized with $50 \mathrm{~mL}$ of methanol and macerated in a magnetic stirrer for 2 hours. Subsequently the, sample was filtered using a coarse filter paper into an evaporation flask and methanol was evaporated at $40^{\circ} \mathrm{C}$. The residue was thereafter redissolved in $50 \mathrm{ml}$ methanol and filtered into vials through 0.45 $\mu \mathrm{m}$ filters. Working conditions of HPLC equipment; injection volume: $20 \mu \mathrm{l}$, flow rate: $1.2 \mathrm{ml} / \mathrm{min}$, column temperature: $30^{\circ} \mathrm{C}$, detectors: DAD, stop time: 28 minutes, mobile phase: $85 \%$ buffer and $15 \%$ acetonitrile, max pressure: 400 bar, wavelength: $240 \mathrm{~nm}$, column features: NC100-5C18-3848 Hichrom and buffer: $84.6 \%$ water and $0.4 \%$ formic acid. Standart curves for oleuropein $(100,200$ and $300 \mathrm{mg} / \mathrm{kg})$, hydroxytyrosol (75, 150 and $300 \mathrm{mg} / \mathrm{kg}$ ) and tyrosol (50, 100 and $200 \mathrm{mg} / \mathrm{kg}$ ) was prepared. Curves of these standart were given in Figure 1.

\section{Sensory analysis of bitterness}

The bitterness of the olives was determined by taking samples at 1 hour intervals during the semidrying process. Following

Table 1. Water, oleuropein, hydroxytyrosol and tyrosol content and sensory bitterness of raw olives.

\begin{tabular}{|c|c|c|c|c|}
\hline $\begin{array}{c}\text { Water } \\
\text { (\%) }\end{array}$ & $\begin{array}{c}\text { Oleuropein } \\
\text { (mg/kg dry } \\
\text { matter) }\end{array}$ & $\begin{array}{c}\text { Hydroxytyrosol } \\
\text { (mg/kg dry matter) }\end{array}$ & $\begin{array}{c}\text { Tyrosol } \\
\text { (mg/kg dry } \\
\text { matter) }\end{array}$ & $\begin{array}{c}\text { Sensory } \\
\text { bitterness } \\
\text { (0-9) }\end{array}$ \\
\hline 62.37 & 640.95 & 2958.39 & 450.03 & 8.9 \\
\hline
\end{tabular}

Table 2. Applied pre-treatments before drying process.

\begin{tabular}{|l|l|c|}
\hline & Pre-treatments & Code of Pre-treatment \\
\hline $\mathbf{1}$ & Immersion in brine $(10 \%)$ at $50^{\circ} \mathrm{C}$ for 10 minutes & Immersion \\
\hline $\mathbf{2}$ & Piercing $\left(\sim 30\right.$ wounds per $\left.\mathrm{cm}^{2}\right)$ & Piercing \\
\hline $\mathbf{3}$ & $\begin{array}{l}\text { Piercing }+ \text { immersion in brine }(10 \%) \text { at } 50^{\circ} \mathrm{C} \text { for } \\
10 \text { minutes }\end{array}$ & Piercing + immersion \\
\hline $\mathbf{4}$ & No pre-treatment (control) & Control \\
\hline
\end{tabular}

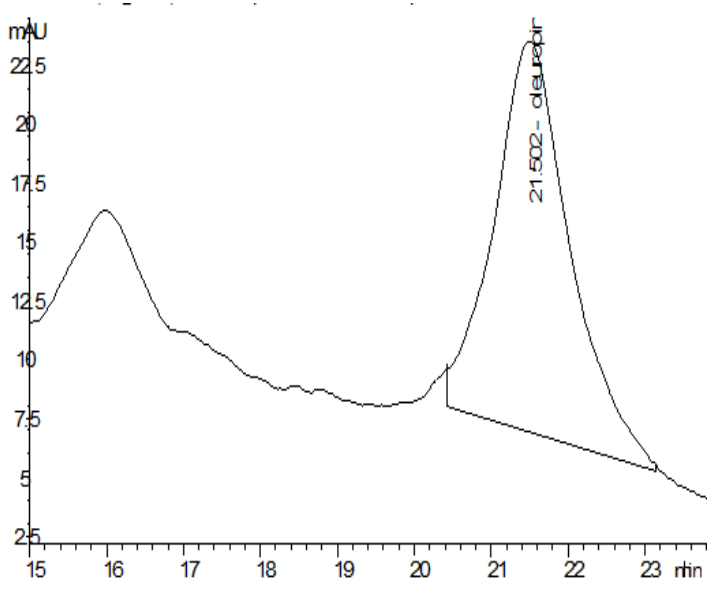

$[A]$

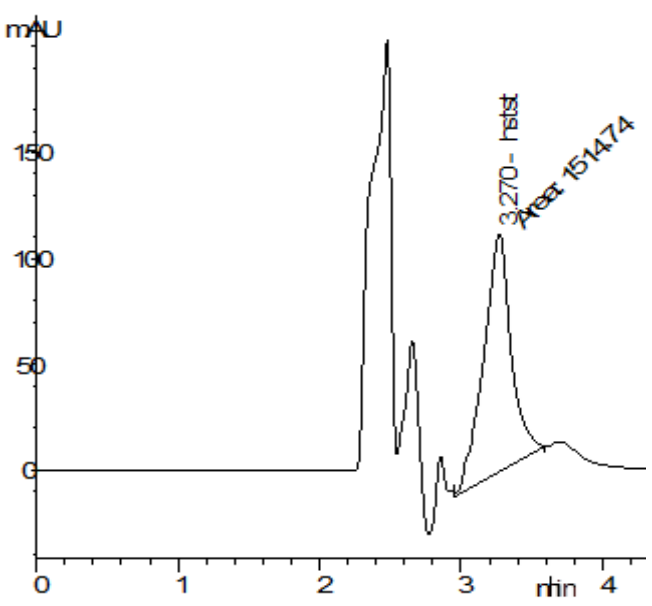

[B]

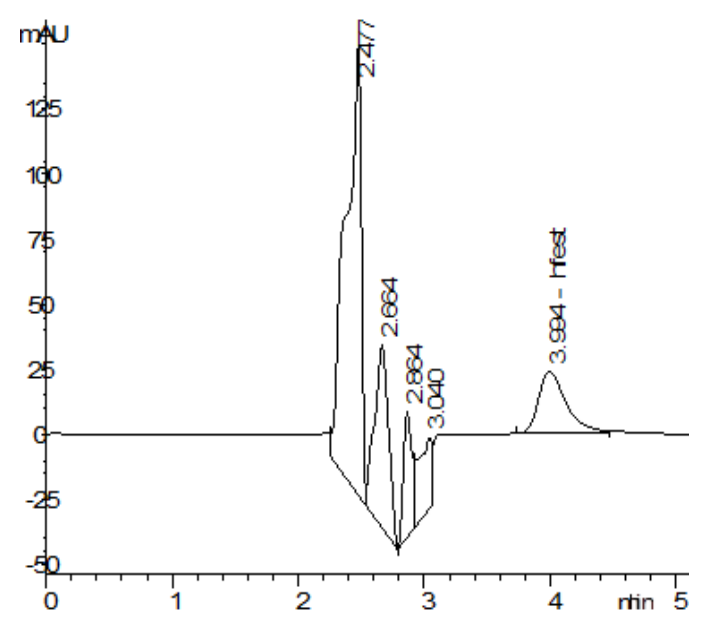

[C]

Figure 1. Chromatograms of oleuropein (a), hydroxytyrosol (b) and tyrosol(c) standarts.

1 hour of cooling of olives at room temperature $\left(\sim 20^{\circ} \mathrm{C}\right)$, sensory bitterness of the olive was evaluated. The panel was comprised of six trained and experienced panelists, aged 31-40 
years. Prior to sensory evaluation, the panelists were trained by using 3 groups of olive samples which differed in oleuropein content. In particular the first group of olives had oleuropein content greater than $500 \mathrm{mg} / \mathrm{kg}$, the second group of olives had oleuropein content between $300-400 \mathrm{mg} / \mathrm{kg}$ and the third group of olives had oleuropein content less than $150 \mathrm{mg} / \mathrm{kg}$. A ten-point scoring scale was employed, in which 9 was set to characterise the most severe bitterness, 5 was set to characterise moderate bitterness and 0 was set to characterize no bitterness. The limit for bitterness tolerance was set at 1.5 on the ten-point scoring scale because a slight bitter taste in table olive is desirable by consumers $[22,23]$. It is worth mentioning that the sensory analysis room was isolated from the external environment (no fluctuation in terms of noise, odor and temperature).

\section{Statistical analysis}

The experiment was conducted using a completely randomized design. Three replication were done for each debittering (pre treatment and semi drying) processes. Analysis of variance was applied with the Duncan multiple comparison test of the means $(p<0.05)$ to determine the presence of significant differences among the samples. Data were analyzed using the PROC GLM procedure of SAS.

\section{Results and Discussion}

In this research, the gradual and uniform decline in sensory bitterness of olives was evaluated during drying because of oleuropein degradation. Target acceptable bitterness level (1.5) was reached with a $31.03-38.24 \%$ weight loss of olive during the drying process. Thus, it is obvious that just the semidrying process with no need for complete drying, is adequate for the production table olives with acceptable bitterness. Water content and the corresponding values of sensory bitterness of olives during the drying process at $40^{\circ} \mathrm{C}$ and $60^{\circ} \mathrm{C}$ are shown in Tables 3 and 4 . At the completion of the drying process 53.45$63.33 \%$ of the initial water content of olives had been removed.

As it seems the pre-treatments which included piercing and piercing with immersion accelerated the reduction of bitterness. This was achieved 1 hour earlier when compared to the other groups that using immersion as well as the control group, during the drying process at $40^{\circ} \mathrm{C}$. On the other hand only the piercing with immersion pre-treatment achieved to reduce the time of debittering process during the drying process at $60^{\circ} \mathrm{C}$. No significant difference for water content and sensory bitterness between immersion pre-treatment and control group was observed in both drying processes (at $40^{\circ} \mathrm{C}$ and $60^{\circ} \mathrm{C}$ ).

Reduction of oleuropein content in olives pre- treated with piercing in combination with immersion and immersion were $12.66 \%$ and $8.43 \%$ respectively. This significant reduction was adequate for olives to reach their acceptable sensory bitterness. One chromatogram of the olive sample is shown in Figure 2.

Table 3. Water content and sensory bitterness change during drying process at $40^{\circ} \mathrm{C}$.

\begin{tabular}{|c|c|c|c|c|c|c|c|c|}
\hline \multirow[b]{2}{*}{$\begin{array}{l}\text { Time } \\
\text { (hour) }\end{array}$} & \multicolumn{2}{|c|}{ Piercing + Immersion } & \multicolumn{2}{|c|}{ Immersion } & \multicolumn{2}{|c|}{ Piercing } & \multicolumn{2}{|c|}{ Control } \\
\hline & Water (\%) & $\begin{array}{c}\text { Sensory } \\
\text { bitterness (0-9) }\end{array}$ & Water $(\%)$ & $\begin{array}{c}\text { Sensory } \\
\text { bitterness } \\
(0-9)\end{array}$ & Water (\%) & $\begin{array}{c}\text { Sensory } \\
\text { bitterness } \\
(0-9)\end{array}$ & Water (\%) & $\begin{array}{c}\text { Sensory } \\
\text { bitterness (0-9) }\end{array}$ \\
\hline 0 & $61.63 \pm 2.12 a$ & $8.4 \pm 0.2 a$ & $60.65 \pm 2.47 a$ & $8.7 \pm 0.6 a$ & $62.62 \pm 1.46 a$ & $8.8 \pm 1.2 a$ & $61.83 \pm 2.32 a$ & $8.8 \pm 1.6 a$ \\
\hline 1 & $48.90 \pm 1.23 b$ & $7.5 \pm 0.3 b$ & $49.57 \pm 1.26 b$ & $7.8 \pm 0.5 b$ & $53.60 \pm 1.08 b$ & $7.5 \pm 1.6 b$ & $50.58 \pm 3.16 b$ & $8.0 \pm 1.0 b$ \\
\hline 2 & $42.31 \pm 2.64 c$ & $7.1 \pm 0.2 b$ & $44.73 \pm 1.33 c$ & $7.4 \pm 0.6 b$ & $47.49 \pm 0.85 c$ & $7.1 \pm 1.3 b$ & $46.39 \pm 1.58 c$ & $7.6 \pm 1.3 b$ \\
\hline 3 & $39.82 \pm 0.8 c$ & $5.2 \pm 0.3 c$ & $40.82 \pm 1.26 d$ & $5.4 \pm 0.4 c$ & $43.19 \pm 0.72 d$ & $5.2 \pm 0.6 c$ & $42.00 \pm 1.26 d$ & $5.6 \pm 1.3 c$ \\
\hline 4 & $35.57 \pm 0.9 d$ & $4.4 \pm 0.2 d$ & $34.52 \pm 1.11 \mathrm{e}$ & $4.5 \pm 0.2 d$ & $37.79 \pm 0.22 e$ & $4.4 \pm 0.5 d$ & $35.17 \pm 1.12 \mathrm{e}$ & $4.7 \pm 0.8 d$ \\
\hline 5 & $32.56 \pm 0.7 \mathrm{de}$ & $3.8 \pm 0.1 \mathrm{de}$ & $30.68 \pm 0.96 f$ & $4.0 \pm 0.2 \mathrm{e}$ & $34.84 \pm 0.16 f$ & $3.8 \pm 0.6 \mathrm{e}$ & $29.99 \pm 1.09 f$ & $4.1 \pm 0.6 \mathrm{de}$ \\
\hline 6 & $30.41 \pm 0.5 e$ & $3.0 \pm 0.1 f$ & $28.44 \pm 0.52 \mathrm{fg}$ & $3.1 \pm 0.1 f$ & $32.02 \pm 0.18 f$ & $3.0 \pm 0.4 \mathrm{e}$ & $30.59 \pm 0.68 f$ & $3.2 \pm 0.3 e$ \\
\hline 7 & $29.50 \pm 0.3 e f$ & $2.3 \pm 0.1 \mathrm{~g}$ & $27.50 \pm 0.41 \mathrm{~g}$ & $2.3 \pm 0.2 \mathrm{~g}$ & $30.76 \pm 0.35 \mathrm{~g}$ & $2.3 \pm 0.1 f$ & $30.40 \pm 0.85 f$ & $2.4 \pm 0.2 f$ \\
\hline 8 & $28.61 \pm 0.5 f$ & $1.3 \pm 0.1 \mathrm{~h}$ & $24.62 \pm 0.26 h$ & $1.7 \pm 0.1 \mathrm{~g}$ & $26.88 \pm 0.46 h$ & $1.4 \pm 0.1 \mathrm{~g}$ & $27.64 \pm 1.10 \mathrm{~g}$ & $1.8 \pm 0.1 \mathrm{~g}$ \\
\hline 9 & - & - & $22.41 \pm 0.15 i$ & $1.3 \pm 0.1 \mathrm{~h}$ & - & - & $26.96 \pm 0.45 g$ & $1.3 \pm 0.1 \mathrm{~h}$ \\
\hline
\end{tabular}

*Numbers with different letters in the same column differ statistically at the $5 \%$ level of significance $(p<0.05)$

Table 4. Water content and sensory bitterness change during drying process at $60^{\circ} \mathrm{C}$.

\begin{tabular}{|c|c|c|c|c|c|c|c|c|}
\hline \multirow[b]{2}{*}{$\begin{array}{l}\text { Time } \\
\text { (hour) }\end{array}$} & \multicolumn{2}{|c|}{ Piercing + Immersion } & \multicolumn{2}{|c|}{ Immersion } & \multicolumn{2}{|c|}{ Piercing } & \multicolumn{2}{|c|}{ Control } \\
\hline & Water (\%) & $\begin{array}{c}\text { Sensory bitterness } \\
(0-9)\end{array}$ & Water (\%) & $\begin{array}{c}\text { Sensory } \\
\text { bitterness } \\
(0-9)\end{array}$ & Water (\%) & $\begin{array}{c}\text { Sensory } \\
\text { bitterness } \\
(0-9)\end{array}$ & Water (\%) & $\begin{array}{c}\text { Sensory } \\
\text { bitterness } \\
(0-9)\end{array}$ \\
\hline 0 & $58.18 \pm 2.30 a$ & $8.6 \pm 1.1 \mathrm{a}$ & $61.07 \pm 2.20 \mathrm{a}$ & $8.8 \pm 0.3 a$ & $63.01 \pm 1.85 a$ & $8.8 \pm 0.6 a$ & $62.29 \pm 1.38 a$ & $8.9 \pm 0.8 a$ \\
\hline 1 & $49.75 \pm 1.62 b$ & $8.2 \pm 1.0 a b$ & $52.25 \pm 1.65 b$ & $8.4 \pm 0.5 a$ & $51.28 \pm 1.26 b$ & $8.1 \pm 0.7 b$ & $57.73 \pm 1.06 b$ & $8.6 \pm 0.9 a$ \\
\hline 2 & $45.82 \pm 1.33 b c$ & $7.4 \pm 1.1 b$ & $44.74 \pm 1.21 \mathrm{c}$ & $7.6 \pm 0.5 b$ & $48.05 \pm 0.95 c$ & $7.4 \pm 0.5 c$ & $53.63 \pm 1.18 b$ & $7.7 \pm 0.6 b$ \\
\hline 3 & $42.32 \pm 1.09 c$ & $6.3 \pm 0.9 c$ & $41.74 \pm 1.03 d$ & $6.4 \pm 0.3 c$ & $44.66 \pm 1.68 d$ & $6.2 \pm 0.3 d$ & $49.41 \pm 1.56 c$ & $6.6 \pm 0.5 c$ \\
\hline 4 & $39.77 \pm 1.62 \mathrm{~d}$ & $5.6 \pm 0.6 d$ & $37.96 \pm 0.95 e$ & $5.7 \pm 0.2 d$ & $41.06 \pm 0.63 e$ & $5.5 \pm 0.2 e$ & $46.41 \pm 0.92 c$ & $5.9 \pm 0.3 d$ \\
\hline 5 & $36.52 \pm 1.36 \mathrm{e}$ & $4.2 \pm 0.3 e$ & $35.25 \pm 0.82 e$ & $4.3 \pm 0.2 e$ & $39.14 \pm 1.05 \mathrm{ef}$ & $4.2 \pm 0.3 f$ & $41.96 \pm 0.77 d$ & $4.4 \pm 0.5 \mathrm{e}$ \\
\hline 6 & $33.14 \pm 0.95 f$ & $4.1 \pm 0.2 \mathrm{e}$ & $32.47 \pm 0.74$ ef & $4.2 \pm 0.3 e$ & $35.85 \pm 0.41 f$ & $4.1 \pm 0.3 f$ & $35.45 \pm 0.46 \mathrm{e}$ & $4.3 \pm 0.2 e$ \\
\hline 7 & $31.56 \pm 0.96 f$ & $3.6 \pm 0.3 f$ & $29.51 \pm 0.63 f$ & $3.7 \pm 0.3 e$ & $33.74 \pm 0.61 f$ & $3.6 \pm 0.2 \mathrm{~g}$ & $33.69 \pm 0.38 \mathrm{e}$ & $3.7 \pm 0.3 f$ \\
\hline 8 & $29.07 \pm 0.42 \mathrm{fg}$ & $2.4 \pm 0.2 \mathrm{~g}$ & $28.36 \pm 0.37 f$ & $2.4 \pm 0.2 f$ & $31.94 \pm 0.85 f g$ & $2.4 \pm 0.2 \mathrm{~h}$ & $31.23 \pm 1.02 \mathrm{ef}$ & $2.5 \pm 0.2 \mathrm{~g}$ \\
\hline 9 & $28.52 \pm 0.16 \mathrm{~g}$ & $1.9 \pm 0.1 \mathrm{~h}$ & $27.81 \pm 0.25 f g$ & $1.9 \pm 0.2 g$ & $32.86 \pm 1.44 f$ & $1.9 \pm 0.1 i$ & $29.26 \pm 0.84 \mathrm{ef}$ & $1.9 \pm 0.3 h$ \\
\hline 10 & $27.15 \pm 0.39 g$ & $1.2 \pm 0.1 i$ & $26.42 \pm 0.32 \mathrm{~g}$ & $1.6 \pm 0.1 \mathrm{~g}$ & $29.36 \pm 0.53 g$ & $1.6 \pm 0.1 \mathrm{i}$ & $28.63 \pm 0.65 f$ & $1.7 \pm 0.1 \mathrm{~h}$ \\
\hline 11 & - & - & $24.93 \pm 0.28 h$ & $1.2 \pm 0.1 \mathrm{~h}$ & $27.46 \pm 0.68 h$ & $1.2 \pm 0.1 \mathrm{j}$ & $26.43 \pm 0.53 g$ & $1.2 \pm 0.2 \mathrm{i}$ \\
\hline
\end{tabular}

*Numbers with different letters in the same column differ statistically at the $5 \%$ level of significance $(p<0.05)$ 
Reduction of oleuropein content in olives during drying at $40^{\circ} \mathrm{C}$ and $60^{\circ} \mathrm{C}$ are shown in Figures 1 and 2, respectively. In particular, oleuropein content was reduced to the desired level 1 hour earlier at $60^{\circ} \mathrm{C}$ compared to that achieved at $40^{\circ} \mathrm{C}$ due to the faster drying process. After drying process, 88.76-91.29\% oleuropein reduction was achieved in olive samples, which had $22.41-28.61 \%$ water content. Thus, piercing plus immersion is an advisable combination of pre-treatments for olive debittering with drying method. The benefits of these pre-treatments are summarized as the significant reduction of the oleuropein content in raw olive and the acceleration of the oleuropein degradation.

Moreover, as it was expected, the piercing in combination with immersion pre-treatments showed higher reduction of the oleuropein, hydroxytyrosol and tyrosol content in olives during the drying process as compared to the other pretreatments. Although the aim of the pretreatment processes and drying was to reduce oleuropein content, however, during these processes hydroxytyrosol and tyrosol losses also occurred and were determined. In this study, higher reduction of hydroxytyrosol $(18.33 \%)$ than of tyrosol content $(10.75 \%)$ was found after the application of piercing+immersion pre-treatments. In parallel to our study, Segovia Bravo KA et al. [24] reported that water solubilizing characteristic of hydroxytyrosol was higher than that of tyrosol.

Hydroxytyrosol is a principal product of oleuropein degradation [25-27]. Oxidation reaction might be related to the loss of hydroxytyrosol and mainly of oleuropein, which showed the greatest concentration reduction in olives during the $24 \mathrm{~h}$ postharvesting period [25]. During drying, oleuropein was degraded to different products; possibly one of them is hydroxytyrosol. Figures 3 and 4 shows the hydroxytyrosol content change of olive during the drying process. Fluctuations of hydroxytyrosol content were observed during the drying process although its content on the final product was reduced as compared to its initial concentration. In the present study, hydroxytyrosol content was affected more compared to tyrosol during drying. This observation could be justified by the fact that given hydroxytyrosol possesses an ortho-diphenol group, it is oxidized much more readily than tyrosol [24].

Few studies reported that hydroxytyrosol and tyrosol were the major phenolic compounds table olives, while oleuropein was not found $[4,28,29]$. Indeed, the present study detected the highest reduction of oleuropein in debittered olive samples. Its content was reduced from $561.45-612.77 \mathrm{mg} / \mathrm{kg}$ dry matter to $45.40-62.97 \mathrm{mg} / \mathrm{kg}$ dry matter $(88.82-92.59 \%$ reduction). The content of hydroxytyrosol and tyrosol was reduced from $2536.37-2908.39$ to $1973.62-2161.35 \mathrm{mg} / \mathrm{kg}$ dry matter (21.69$28.01 \%$ loss) and from $411.58-459.04$ to $210.28-307.92 \mathrm{mg} / \mathrm{kg}$ dry matter (27.02-51.41\% loss), respectively.

Reductions and fluctuations were determined of tyrosol content in olives during the drying process at both $40^{\circ} \mathrm{C}$ and $60^{\circ} \mathrm{C}$. Changes in tyrosol content are shown in Figures 5 and 6 . Higher fluctuations were determined during drying at $60^{\circ} \mathrm{C}$. Although

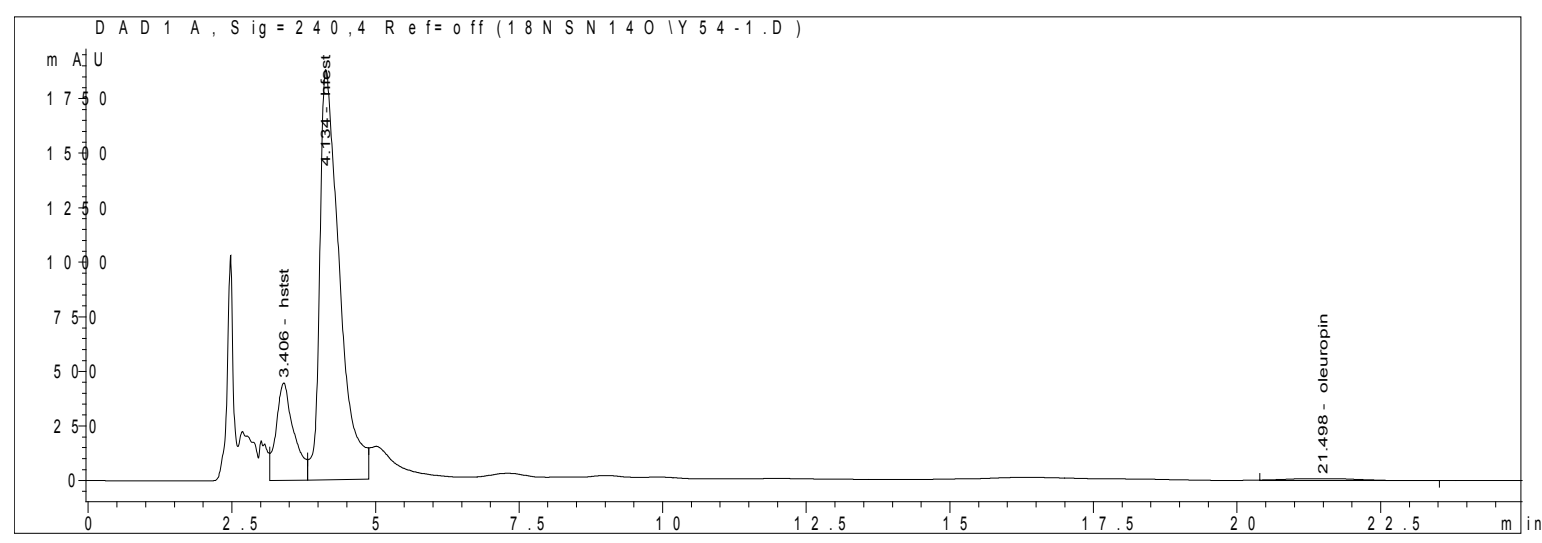

Figure 2. Chromatogram of the olive sample.

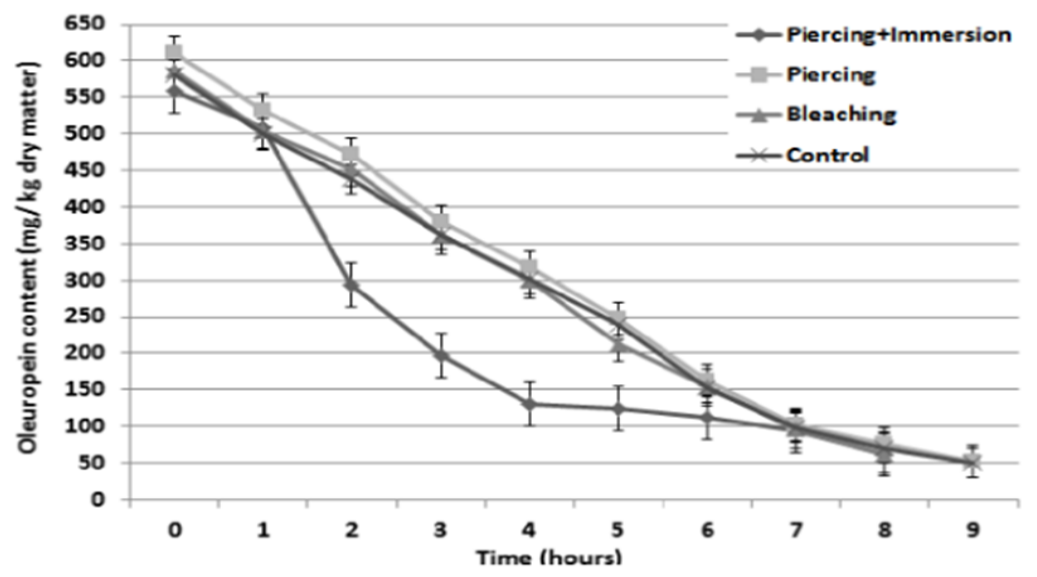

Figure 3. Change of oleuropein content during the application of different debittering procedures using the drying process at $60^{\circ} \mathrm{C}$. 


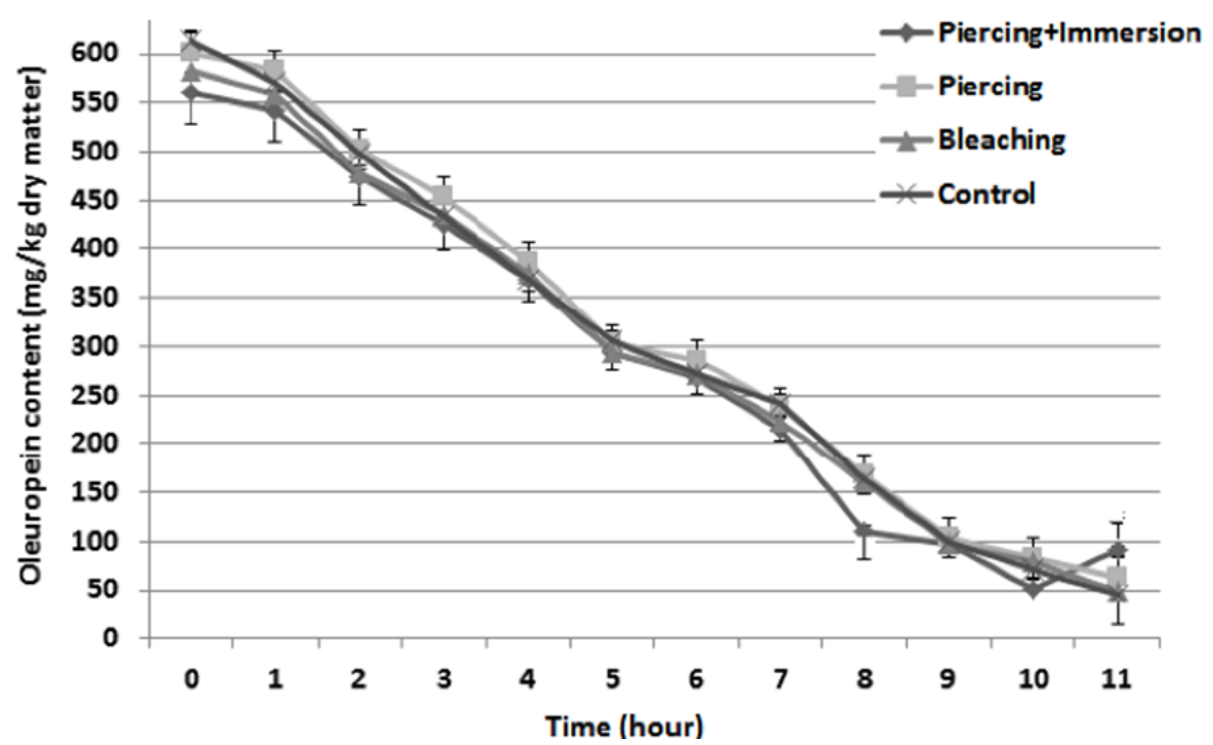

Figure 4. Change of oleuropein content during the application of different debittering procedures using the drying process at $40^{\circ} \mathrm{C}$.

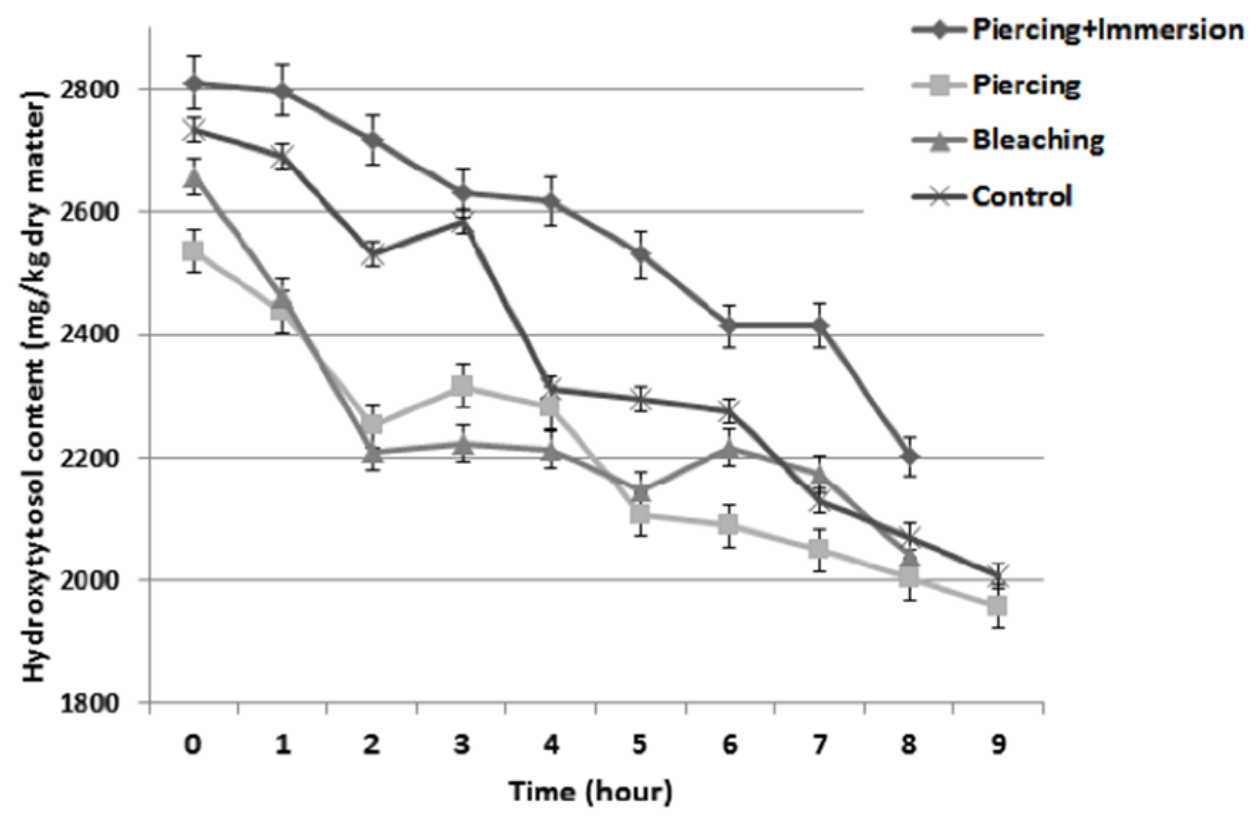

Figure 5. Change of hydroxytyrosol content during the application of different debittering procedures using the drying process at $60^{\circ} \mathrm{C}$.

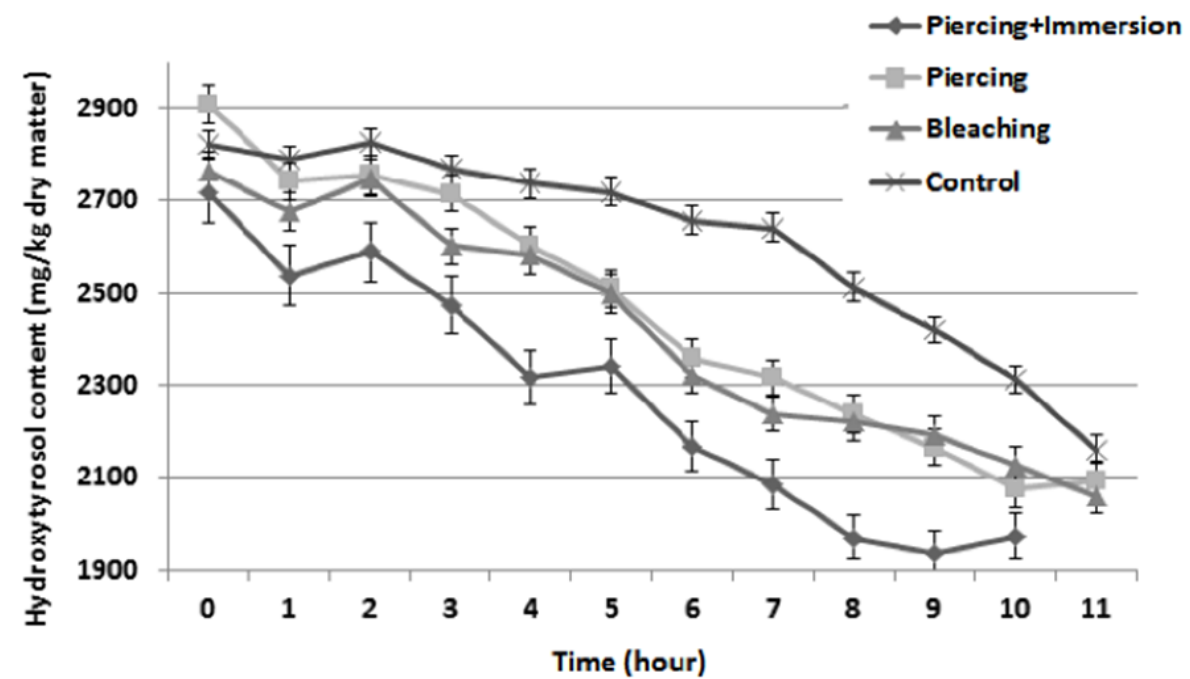

Figure 6. Change of hydroxytyrosol content during the application of different debittering procedures using the drying process at $40^{\circ} \mathrm{C}$. 
there was nearly a linear decrease of oleuropein content, a fluctuation of tyrosol content's reduction degree was observed in olives. Indeed, the higher the drying temperature, the higher the intensity of fluctuations of tyrosol content during drying.

Antioxidant activity of these phenolic compounds was reported as following order: tyrosol < oleuropein $<$ hydroxytyrosol and degradation rate of phenolic compounds were positively correlated to their antioxidant activity [7]. In this study, after debittering, the reduction of these phenolics was in the following order: hydroxytyrosol $<$ tyrosol $<$ oleuropein. Oleuropein content was reduced more than tyrosol content. Hydroxytyrosol is sensitive to oxidation, so that hydroxytyrosol showed the highest loss after the drying process (Figures 7 and 8). However, according to the findings of Chimi et al. and Tuck and Hayballa after drying, oleuropein showed higher reduction compared to that of hydroxytyrosol. This could be justified by the fact that oleuropein was broken down into hydroxytyrosol. Thus, hydroxytyrosol content was increased after processing, tyrosol content showed lesser reduction after oxidation compared to hydroxytyrosol and oleuropein which is in agreement with result of this study. Probably, the fluctuations on hydroxytyrosol and tyrosol contents were observed due to the combined effect of temperature and oxidation [30].

\section{Conclusion}

In this study, oleuropein, hydroxytyrosol and tyrosol content and sensory bitterness have been determined for the first time in literature during olive drying for debittering purpose.

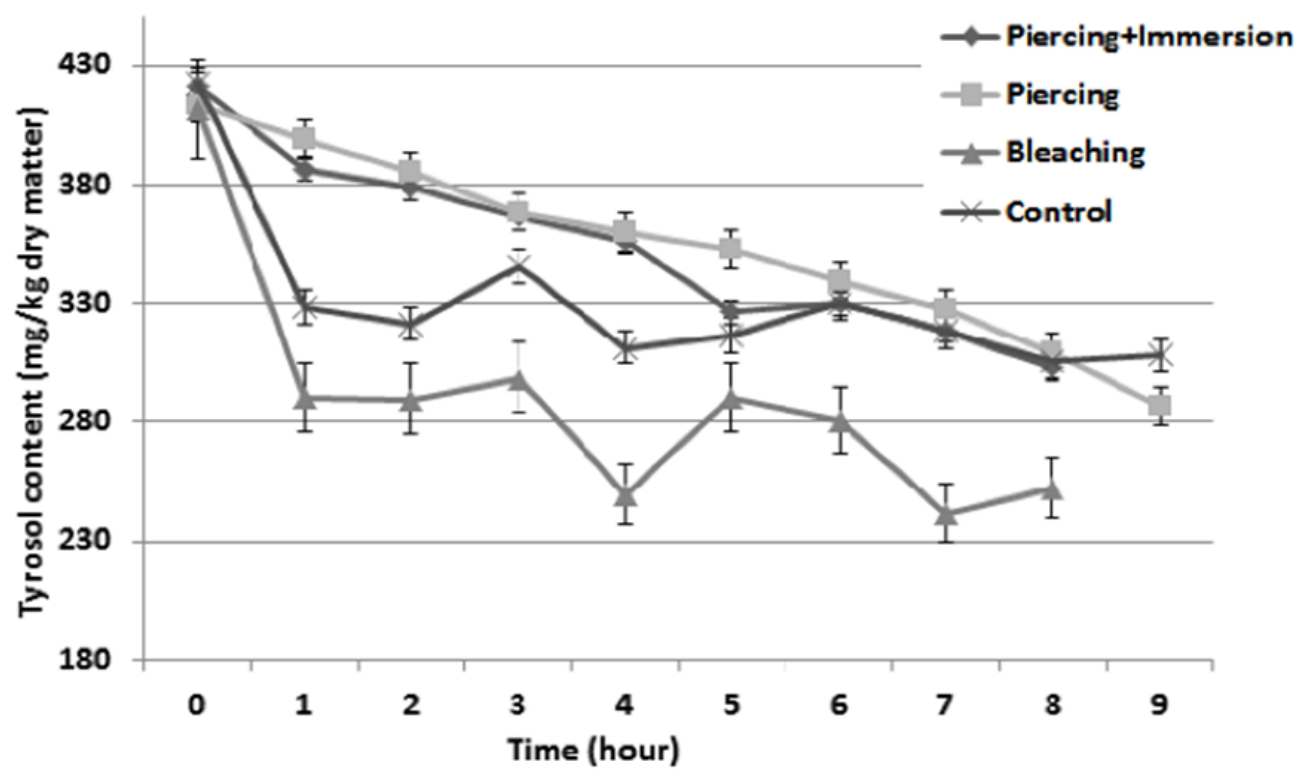

Figure 7. Change of tyrosol content during the application of different debittering procedures using the drying process at $60^{\circ} \mathrm{C}$.

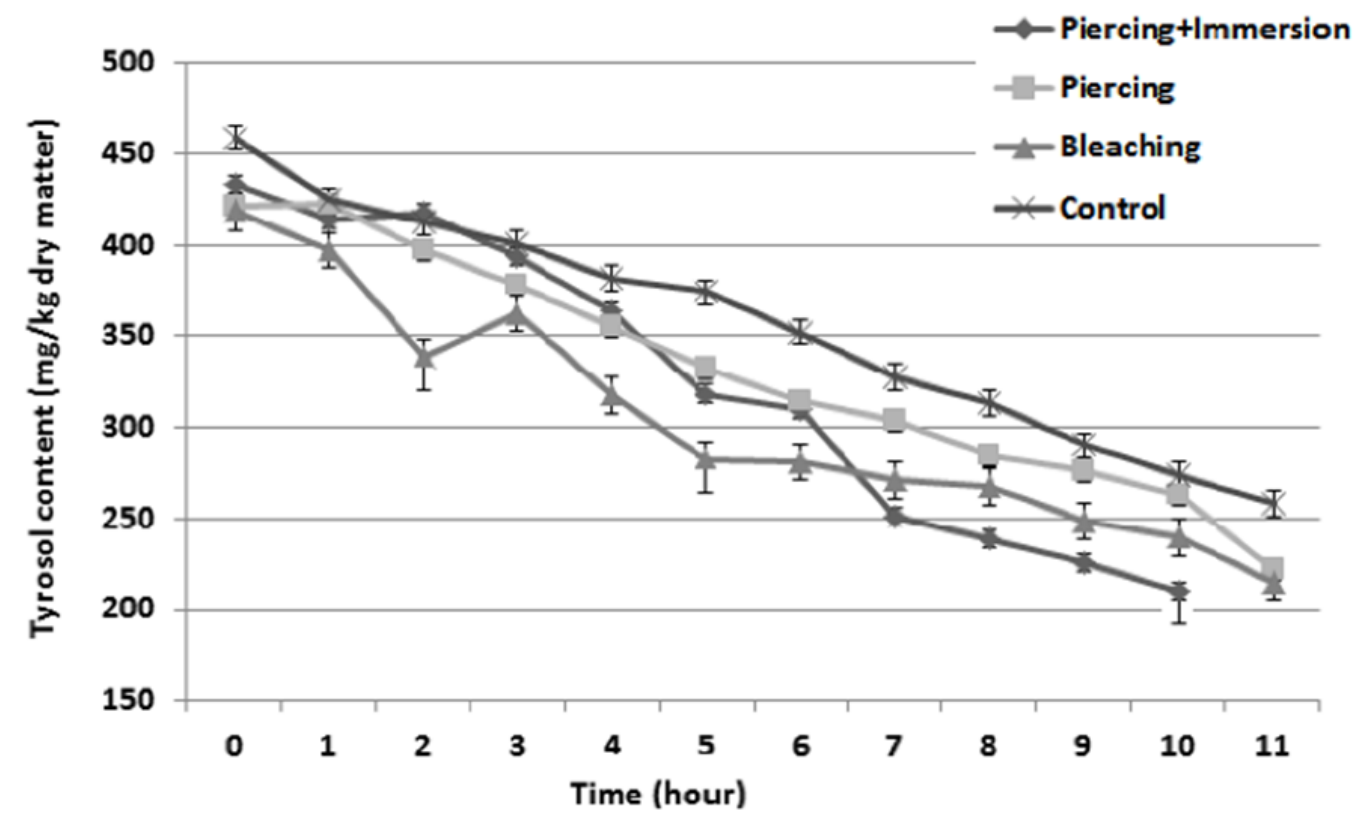

Figure 8. Change of tyrosol content during the application of different debittering procedures using the drying process at $40^{\circ} \mathrm{C}$. 
Piercing in combinatin with immersion processes seems to be the advisable pre-treatments for producers. This combination reduces oleuropein content of raw olive and accelerates the oleuropein degradation by facilitating the drying behavior of the olive. These findings of the present study suggest that drying with pre-treatments can be used as a new table olive debittering method. Advantages of this debittering method includes; short processing time, avoidance of use of chemical agents, low salt content of final table olives and formation of reduced amounts of waste water.

\section{References}

1. Civantos L. Oliviculture in the World and in Spain. Junta de AndalucoAa-Ediciones MundiPrensa, Madrid. 1998:17-34.

2. Ryan D, Robards K. Phenolic compounds in olives. Analyst. 1998;123:31-44.

3. Ryan D, Robards K, Prenzler P, et al. Liquid chromatography with electrospray ionisation mass spectrometric detection of phenolic compounds from Olea europaea. J Chromatogr A. 1999;855(2):529-37.

4. Zoidou E, Melliou E, Gikas E, et al. Identification of Throuba Thassos, a traditional Greek table olive variety, as a nutritional rich source of oleuropein. J Agric Food Chem. 2010;58(1):46-50.

5. Brenes M, Castro A. Transformation of oleuropein and its hydrolysis products during Spanish-style green olive processing. J Sci Food Agric. 1998;77:353-8.

6. Brenes M, Garcia P, Romero C, et al. Treatment of green table olive waste waters by an activated-sludge process. $\mathrm{J}$ Chem Technol Biotechnol. 2000;75(6):459-63.

7. Sanchez AH, Rejano L, Montano A, et al. Utilization at high $\mathrm{pH}$ of starter cultures of Lactobacilli for Spanish-style green olive fermentation. Int J Food Microbiol. 2001;67(12):115-22.

8. Medina E, Romero C, De Castro A, et al. Inhibitors of lactic acid fermentation in Spanish-style green olive brines of the Manzanilla variety. Food Chem. 2008;110(4):932-7.

9. Panagou EZ, Tassou CC, Skandamis PN. Physicochemical, microbiological, and organoleptic profiles of Greek table olives from retail outlets. J Food Prot. 2006;7:1732-8.

10. Abriouel H, Benomar N, Lucas R, et al. Culture-independent study of the diversity of microbial populations in brines during fermentation of naturally-fermented Alorena green table olives. Int J Food Microbiol. 2011;144(3):487-96.

11. Pereira JA, Pereira AP, Ferreira IC, et al. Table olives from Portugal: phenolic compounds, antioxidant potential, and antimicrobial activity. J Agric Food Chem. 2006;54(22):8425-31.

12. Othmana NB, Roblainb D, Chammena N, et al. Antioxidant phenolic compounds loss during the fermentation of Chetoui olives. Food Chem. 2009;116(3):662-9.

13. Rivas FJ, Beltran FJ, Gimeno O. Joint treatment of wastewater from table olive processing and urban wastewater. Integrated ozonation - aerobic oxidation. Chem Eng Technol. 2000;23(2):177-181.

14. Marsilio V, Lanza B, Campestre C, et al. Oven-dried table olives: textural properties as related to pectic composition. J Sci Food Agric. 2000;80(8):1271-6.

15. Cardoso SM, Mafra I, Reis A, et al. Traditional and industrial oven-dry processing of olive fruits: influence on textural properties, cell wall polysaccharide composition, and enzymatic activity. Eur Food Res Technol. 2009;229(3):415-425.

16. International Olive Council. Guide for the determination of the characteristics of oil-olives. COI/OH/Doc. No 1 Madrid. 2011.

17. Degirmencioglu N, Gurbuz O, Degirmencioglu A, et al. Effect of MAP and vacuum sealing on sensory qualities of dry-salted olive. Food Sci Biotechnol. 2011;20(5):1307-13.

18. Frankel E. A critical literature review on the processing of table olives. Lipid Technol. 2011;23(10):223-6.

19. Mafra I, Lanza B, Reis A, et al. Effect of ripening on texture, microstructure and cell wall polysaccharide composition of olive fruit (Olea europaea). Physiol Plant. 2001;111(4):43947.

20. Morello JR, Romero MP, Motilva MJ. Effect of the maturation process of the olive fruit on the phenolic fraction of drupes and oils from Arbequina, Farga, and Morrut cultivars. J Agric Food Chem. 2004;52(19):6002-9.

21. Lanza B. Nutritional and sensory quality of table olives. In: Muzzalupo I (ed.). Olive Germplasm- The Olive Cultivation, Table Olive and Olive Oil Industry in Italy. IntechOpen. 2012:343-72.

22. Panagou EZ, Tassou CC, Katsaboxakis KZ. Microbiological, physicochemical and organoleptic changes in dry salted olives of Thassos variety stored under different modified atmospheres at 4 and $20^{\circ} \mathrm{C}$. Int $\mathrm{J}$ Food Sci Technol. 2002;37(6):635-41.

23. Fernandez-Bolanos J, Felizon B, Brenes M, et al. Hydroxytyrosol and tyrosol as the main compounds found in the phenolic fraction of steam-exploded olive stones. J American Oil Chemists Society. 1998;75(11):1643-9.

24. Segovia Bravo KA, Jaren Galan M, Garcia GP, et al. Browning reactions in olives: Mechanism and polyphenols involved. Food Chem. 2009;114(4):1380-5.

25. Lee Huang S, Huang PL, Zhang D, et al. Discovery of smallmolecule HIV-1 fusion and integrase inhibitors oleuropein and hydroxytyrosol: Part I. Integrase inhibition. Biochem Biophys Res Commun. 2007;354(4):872-878.

26. Erbay Z, Icier F. Optimization of hot air drying of olive leaves using response surface methodology. J Food Eng. 2009;91(3):533-41.

27. Blekas G, Vassilakis C, Harizanis C, et al. Biophenols in table olives. J Agric Food Chem. 2002;50(13):3688-92. 
28. Boskou G, Salta FN, Chrysostomou S, et al. Antioxidant capacity and phenolic profile of table olives from the Greek market. Food Chem. 2006;94:558-64.

29. Chimi H, Cillard J, Cillard P, et al. Peroxyl and hydroxyl radical scavenging activity of some natural phenolic antioxidants. J American Oil Chemists Society. 1991;68(5):307-12.

30. Tuck KL, Hayballa PJ. Major phenolic compounds in olive oil: metabolism and health effects. J Nutr Biochem. 2002;13(11):636-44.

\section{*Correspondence to:}

Yasin Ozdemir

Department of Food Technology

Ataturk Central Horticultural Research Institute

Yalova

Turkey

Tel: 02268142520 - 1652

E-mail: gidaciyasin@hotmail.com 